\title{
Engineering of Adult Neurogenesis and Gliogenesis
}

\author{
Benedikt Berninger $^{1}$ and Sebastian Jessberger ${ }^{2}$ \\ ${ }^{1}$ Adult Neurogenesis and Cellular Reprogramming, Institute of Physiological Chemistry \& Focus Program \\ Translational Neuroscience, University Medical Center, Johannes Gutenberg University Mainz, \\ 55128 Mainz, Germany \\ ${ }^{2}$ Brain Research Institute, University of Zurich, 8057 Zurich, Switzerland \\ Correspondence: berningb@uni-mainz.de; jessberger@hifo.uzh.ch
}

\begin{abstract}
Neural stem/progenitor cells (NSPCs) retain their ability to generate newborn neurons throughout life in the mammalian brain. Here, we describe how recently developed virusand transgenesis-based techniques will help us (1) to understand the functional effects of neurogenesis in health and disease, (2) to design novel approaches to harness the potential for NSPC-associated endogenous repair, and (3) to induce the generation of neurons outside the main neurogenic niches in the adult brain.
\end{abstract}

$T^{\text {he }}$ he fact that neural stem/progenitor cells (NSPCs) persist in the adult brain, challenged previously held concepts of brain function in health and disease and opened novel possibilities to treat neurological disease by harnessing the NSPC-associated potential for brain repair (Gage 2000; Alvarez-Buylla and Lim 2004; Gage and Temple 2013). However, over the last decade, it has become clear that targeting NSPCs for repair requires the detailed understanding of the biology of NSPCs and the underlying cellular and molecular mechanisms that govern the distinct steps of neural development from dividing NSPCs to integrating neurons (Ming and Song 2011). Based on findings obtained by aiming to understand the basic mechanisms of adult neurogenesis, a number of technical advancements have substantially increased our toolbox to manipulate NSPC activity in vivo and/or subsequent neuronal integration in the adult brain. Furthermore, our understanding of the mechanisms regulating neural differentiation has substantially improved over the last years making it now possible to redirect the fate of NSPC-derived, newborn cells in the adult brain (Hack et al. 2005; Jessberger et al. 2008; Brill et al. 2009). Besides these novel tools that target NSPCs in their endogenous niches, basic understanding of the underlying neuronal differentiation of NSPCs in the adult brain enabled novel approaches to induce the generation of neurons also in nonneurogenic regions throughout the adult brain (Jessberger and Gage 2009; Amamoto and Arlotta 2014; Heinrich et al. 2015). In addition, novel cellular sources such as NSPCs derived from induced pluripotent stem cells (iPSCs), will enable us to study mechanisms of NSPC activity and neuro-

Editors: Fred H. Gage, Gerd Kempermann, and Hongjun Song

Additional Perspectives on Neurogenesis available at www.cshperspectives.org

Copyright (C) 2016 Cold Spring Harbor Laboratory Press; all rights reserved; doi: 10.1101/cshperspect.a018861

Cite this article as Cold Spring Harb Perspect Biol 2016;8:a018861 
nal differentiation in healthy and diseased human tissue and may also represent a novel source for exogenous cell-replacement strategies ( Yu et al. 2013, 2014).

\section{MANIPULATING LEVELS OF ADULT NEUROGENESIS}

Over the last decade, a plethora of approaches have been developed to reduce or to enhance levels of adult neurogenesis with the aim to test experimentally the functional contribution of newborn neurons to adult behavior (Deng et al. 2010). Initially, cytostatic drugs or ionizing irradiation impairing cell proliferation were used (and are still in use, e.g., Shors et al. 2001;
Snyder et al. 2005; Saxe et al. 2006). However, given that the whole organism depends on proper levels of cell proliferation and the fact that irradiation also injures postmitotic cells, these approaches are likely to be associated with unwanted side effects that are bound to complicate the interpretation of behavioral tests (Fig. 1). Thus, the focus over the years has been to develop genetic or virus-based strategies to manipulate levels of neurogenesis. The most common principle used is to either kill proliferating NSPCs or to impair (or in the case of enhancing neurogenesis to increase) the survival of newborn neurons (Deng et al. 2010). For example, a number of different promoters were transgenically modified to drive thymidine kinase expres-

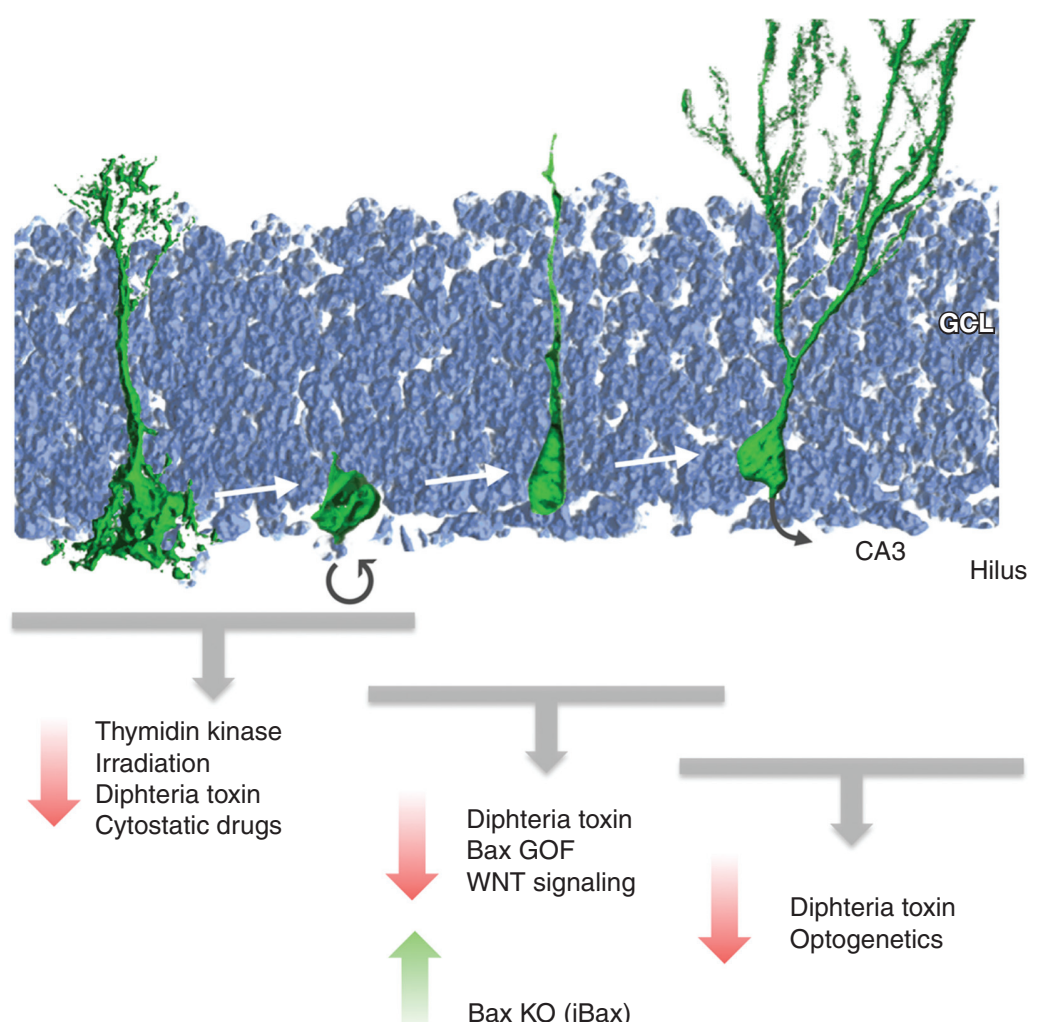

Figure 1. Approaches to engineer levels of adult neurogenesis. Depicted are the developmental steps from largely quiescent radial glia-like neural stem cells through proliferative nonradial neural stem/progenitor cells (NSPCs) generating newborn neurons that mature and functionally integrate over the course of several weeks in the rodent hippocampus. Experimental strategies to reduce or to enhance levels act on distinct stages from the dividing NSPC to the newborn neuron. GCL, granule cell layer; CA3, cornu ammonis area 3. (Figure courtesy of Dr. S.M.G. Braun, Brain Research Institute, Zurich, Switzerland.) 
sion in adult NSPCs that on gancyclovir (GCV) administration results in the generation of a toxic metabolite that selectively kills dividing cells (Fig. 1) (Garcia et al. 2004; Saxe et al. 2006, 2007; Deng et al. 2009). Most laboratories used the regulatory elements of the nestin gene (coding for an intermediate filament that is highly enriched in NSPCs) or the promoter sequences driving glial fibrillary acidic protein (GFAP) (another intermediate filament that is expressed in NSPCs but also in a large set of classical astrocytes throughout the brain).

Using these approaches, a substantial (and even complete) loss of neurogenesis can be achieved that is either chronic or transient (Garcia et al. 2004; Deng et al. 2009). However, one potential disadvantage of using the nestin or gfap promoter is that these regulatory sequences may mediate also active sites of transgene transcription in other somatic stem-cell compartments, such as in the intestines or skin stemcell niches (Bush et al. 1998; Mignone et al. 2007). The same concern holds true for nestinor $g f a p$-promoter-mediated deletion of survival genes resulting in the loss of newborn cells ( Dupret et al. 2008). An elegant approach to restrict cell death to the neuronal progeny of nestin-expressing cells has been achieved by selectively expressing diphtheria toxin A (DTA) (killing cells on expression) in nestin expression-fatemapped cells that have an active neuron-specific enolase (NSE) promoter (Imayoshi et al. 2006, 2008).

In addition to transgenesis-based approaches, viral vectors have been successfully used to reduce levels of neurogenesis, for example, by impairing proper WNT signaling (Fig. 1) (Lie et al. 2005; Jessberger et al. 2009). Despite the advantages of high temporal and spatial control (and the usability of rats which is advantageous for a number of behavioral experiments), there is the apparent risk for off-target effects if the targeted signaling pathways are not completely specific for NSPC/neuronal differentiation (e.g., WNT signaling appears to be also involved in synaptic function/remodeling of mature neurons and not only for the generation of new neurons) (Cerpa et al. 2011). Very recently, optogenetic tools have been developed allowing the selective expression of hyperpolarizing (or depolarizing) opsins in newborn neurons in the adult brain ( $\mathrm{Gu}$ et al. 2012). This represents a novel and exciting tool to characterize the functional contribution of newborn neurons (Fig. 1). However, it is also clear that a circuitry certainly responds "differently" to the acute silencing of neuronal populations compared with the situation in which this population is "missing," which may be the more relevant situation when it comes to experimentally testing the role of new neurons in the disease context. An interesting alternative to optogenetics is the use of designer receptors exclusively activated by designer drugs (DREADDs) (Sternson and Roth 2014). For instance, virus-mediated expression of a designer $G$ protein-coupled receptor (hM3Dq) selectively activated by the pharmacologically inert, orally bioavailable drug clozapine- $N$-oxide $(\mathrm{CNO})$ allowed for assessing the ability of newborn dentate granule neurons to activate parvalbumin-positive interneurons (Temprana et al. 2015).

In contrast, to the progress made over the last decades to reduce neurogenesis, there are very few tools available to enhance neurogenesis. One elegant approach has been to delete proapoptotic genes selectively in adult-born cells, leading to a doubling of newborn neurons (Fig. 1) (Sahay et al. 2011). Excitingly, these transgenic mice (called iBaxNes) allowed for testing of potential gain-of-function effects of increased neurogenesis that could be indeed experimentally observed in the behavioral context of dentate gyrus-mediated pattern separation (Sahay et al.2011). However, a potential concern with this approach may be that deletion of bax increases survival of cells that would be otherwise sorted out-by poorly understood, activity-dependent selection criteria (Tashiro et al. 2007). Thus, it is possible that cells are rescued that do not meet certain criteria for proper integration. Thus, future approaches may target rather NSPC proliferation, allowing for subsequent proper functional selection with regard to survival and functional integration.

Be that as it may, over the last decade, immense progress has been made to develop novel tools allowing for manipulating levels of neuro- 
genesis and to test the functional contribution of the resulting new neurons for adult brain behavior. However, the specificity and temporal control of loss- and gain-of-function will need to be further optimized to improve our understanding how new neurons shape the functional connectivity of the adult dentate circuitry in health and disease.

\section{ENABLING NEUROGENESIS OUTSIDE ITS NATURAL NICHES}

Neurogenesis is restricted to few areas within the adult brain (Zhao et al. 2006), but an unfulfilled clinical need for new neurons arises in many more brain regions in the context of human disease or trauma. Although transplantation is potentially a viable approach to address this need (Lindvall 2013), here, we discuss recent work focusing on the possibility of converting endogenous nonneuronal cells into induced neurons (reviewed in Heinrich et al. 2015). Likewise, a similar approach may serve to regenerate oligodendroglia for those disease scenarios in which this cell type degenerates.

\section{Reprogramming of Central Nervous System (CNS) Glia into Induced Neurons}

One of the earliest studies in this direction was work by Kondo and Raff showing that sequential exposure to specific extracellular signals could reprogram oligodendrocyte precursor cells (OPCs) to multipotential CNS (central nervous system) stem cells (Kondo and Raff 2000). It was recognized that this reprogramming is accompanied by chromatin remodeling resulting in the reactivation of the sox2 gene (Kondo and Raff 2004), a key transcription factor in neural stem cells, but also of pivotal importance during reprogramming toward pluripotency (Sarkar and Hochedlinger 2013).

Based on the recognition that neural stem cells both during development and in the adult have a radial glia identity sharing many molecular and cellular features with parenchymal astrocytes (Doetsch et al. 1999; Malatesta et al. 2000; reviewed in Kriegstein and AlvarezBuylla 2009), Magdalena Götz and colleagues hypothesized that astroglia may perhaps retain some potential of generating neurons with appropriate transcriptional cues provided that elicit a neuronal program (Costa et al. 2010). Having shown that pax6 is required for neurogenesis from radial glia of the cerebral cortex, pax6 was also the first transcription factor gene tested for its capacity to reprogram early postnatal mouse astroglia into induced neurons in vitro. Indeed, forced expression of pax 6 elicited a neurogenic response in these cells (Heins et al. 2002). Using this experimental paradigm, several studies then examined the effect of other neurogenic transcription factors, such as neurog2, ascl1, dlx2, and neurod1 (Berninger et al. 2007; Heinrich et al. 2010; Guo et al. 2014), well known for their important roles during embryonic and adult neurogenesis and thus qualifying them as potential reprogramming factors (Amamoto and Arlotta 2014). It turned out that retrovirus-mediated neurog2 expression could induce in early mouse astroglia the expression of a cascade of transcription factors (Tbr2 and Tbr1) that hallmark glutamatergic neurogenesis (Berninger et al. 2007) and convert these into fully functional synapse-forming neurons of glutamatergic neuron identity (Heinrich et al. 2010). This very same astroglia could be reprogrammed into neurons of the GABAergic lineage by forced expression of ascl1 or $d l x 2$. This data thus show that a single transcription factor suffices to reprogram early postnatal astrocytes into functional neurons. But recent work indicates that even in culture, astrocytes quickly lose their permissiveness to single transcription factor reprogramming (Maserdotti et al. 2015). Five days after exposure to differentiating conditions, astrocytes derived from mouse postnatal cortex no longer reprogram following induced Neurog2 expression. This loss of reprogramming permissiveness appears to be mediated by REST (RE-1 silencing transcription factor), which prevents Neurog2 of binding to its target sites. However, failure of reprogramming can be bypassed by directly activating some of the Neurog2 targets, such as NeuroD4. This data then support the notion that reprogramming permissiveness is strongly dependent on the epigenetic state of the cells to 
Engineering of Adult Neurogenesis and Gliogenesis

be lineage-converted. Likewise, the highly different permissiveness of fibroblasts and keratinocytes to Ascl1-induced reprogramming appear to be consequence of their specific and distinct chromatin signature at Ascl1 targets (Wapinski et al. 2013). After all, this leads to the, probably not very surprising, conclusion that cells that have undergone considerable epigenetic maturation will prove hardest to reprogram (Fig. 2).

Thus, it is encouraging that the adult human brain does contain cells that appear to be amenable to reprogramming into induced neurons. Aiming at converting cells isolated from human brain biopsies, we identified cells expressing a battery of pericytic markers in vitro that can be converted following combined expression of sox2 and ascl1 (Karow et al. 2012). Here, as in maturing astrocytes, the proneural gene (ascl1) alone fails to reprogram, suggesting that the effect of sox 2 coexpression may consist in rendering Ascl1 targets more accessible (see discussion below). Interestingly, pericytes emerge as new players in CNS scar formation, a response that requires deattachment from microvessels to which these cells are associated under healthy conditions (Goritz et al. 2011). In addition to glial cells, such "reactive" pericytes may represent an interesting target for in vivo reprogramming (Karow et al. 2012).

\section{In Vivo Reprogramming in the Adult Brain}

Attempts of direct lineage reprogramming of glial cells into neurons have now been carried on to the in vivo level in the cerebral cortex, striatum, and spinal cord (Buffo et al. 2005; Grande et al. 2013; Guo et al. 2014; Heinrich et al. 2014). Already, an early study from the Götz laboratory addressed the possibility of converting proliferative cells in the injured cerebral cortex into induced neurons and found that expression of Pax6 or repression of Olig2 transcriptional targets resulted in the transient emergence of doublecortin (DCX)-positive cells (Buffo et al. 2005). More recently, it was found that in the injured cerebral cortex in vivo fate conversion of nonneuronal cells by

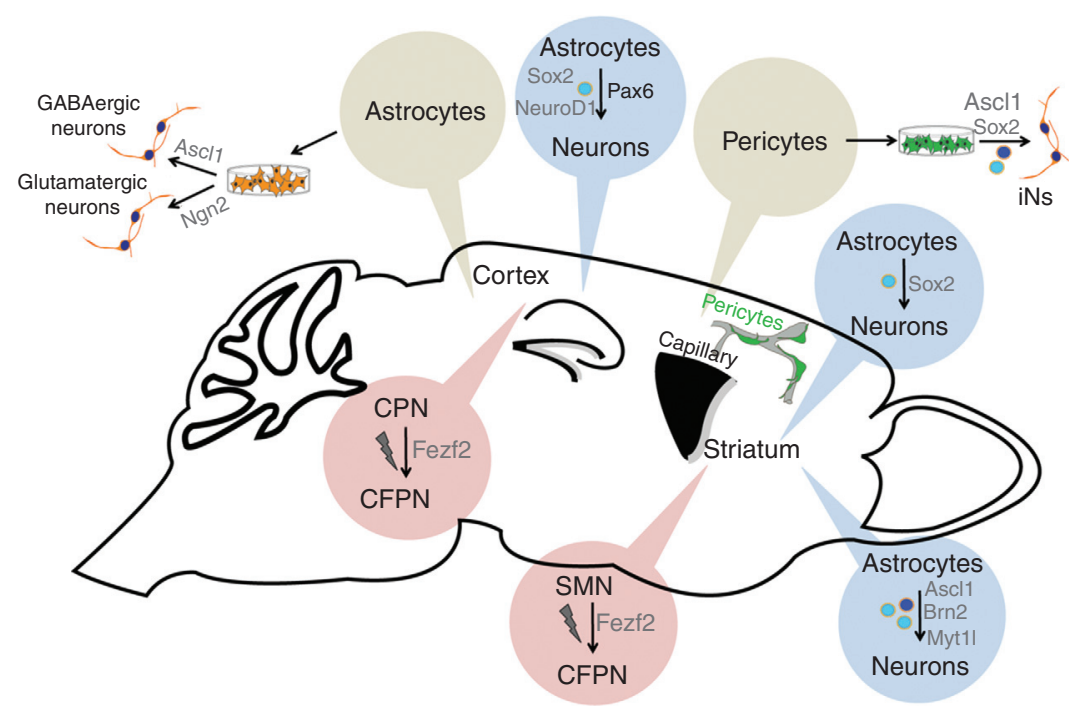

Figure 2. Engineering neurogenesis outside the classical neurogenic niches. Depicted are the different in vitro and in vivo approaches scrutinized so far for reprogramming nonneuronal cells into induced neurons. Likewise, highlighted are in vivo experiments assessing the possibility of converting distinct types of neuronal progenitors or neurons into another via in utero electroporation. MSN, medium spiny neuron; CPN, callosal projection neuron; CFPN, corticofugal projection neuron. (Figure courtesy of Dr. M. Karow, Institute of Physiology, LMU Munich, Germany.) 
neurogenic fate determinants can be influenced by simultaneous delivery of growth factors (Grande et al. 2013). However, in both studies, the precise cellular source of the induced neuronal cells remained unknown.

Previously, pioneering work from the Wernig laboratory had shown that three factors, ascl1, brn2, and myt1l, can reprogram fibroblasts into induced neurons (Vierbuchen et al. 2010). Torper et al. (2013) now delivered this factor triad into the adult striatum via cre-inducible lentiviral vectors. Indeed, they found NeuN-positive cells that were also reporter-positive (an indicator of recombination) in a transgenic mouse line expressing cre under control of regulatory elements of the gfap gene (gfap-cre), providing evidence for direct astrocyte-to-neuron conversion in situ (Fig. 2). With a caveat for some leakiness of $g f a p$ promoter activity, this study provided compelling evidence for an astroglial origin of the reprogrammed cells. However, it remains unknown whether the virustargeted glial cells were reactive (as a response to the virus injection) or nonreactive parenchymal astrocytes. In fact, recent work from the Frisén laboratory has suggested that striatal astrocytes possess a latent neurogenic program, under healthy conditions restrained by Notch signaling, but unleashed following injury (Magnusson et al. 2014).

In contrast, a recent study from the Zhang laboratory has provided evidence that forced expression of sox 2 alone can drive striatal astrocytes (as evidenced by several lines of genetic fate-mapping experiments) toward early stages of neurogenesis (Fig. 2) (Niu et al. 2013). Surprisingly, these data suggest that the reprogrammed cells do not acquire a neural-stemcell identity (as evidenced by absence of nestin expression at any stage), as one might have expected at first glance, given the known role of sox2 in neural stem cells. Nonetheless, these cells incorporated bromodeoxyuridine (BrdU) and apparently proliferated as DCX-positive neuroblasts. Although these cells fail to acquire a mature neuronal state when left alone, they develop into postmitotic neurons with remarkable electrophysiological properties when exposed to the neurotrophin brain-derived neuro- trophic factor (BDNF) and the natural bone morphogenetic protein (BMP) inhibitor noggin or treated with a histone deacetylase inhibitor. Of note, we found that forced sox 2 expression can also convert reactive glia in the cerebral cortex of mice following stab wound injury (Heinrich et al. 2014). Remarkably, this effect was strictly dependent on prior injury suggesting that the lesioning rendered the cells more permissive to glia-to-neuron conversion. Moreover, to our surprise, genetic fate mapping revealed that the cell population undergoing fate conversion was not the astrocytic compartment but NG2 glia. Despite the fact that the physiological role of these cells in grey matter is still largely enigmatic, they can function as oligodendrocyte progenitor cells (Dimou and Gotz 2014). Hence, it might be possible that it is their status as progenitors that renders these cells more permissive to lineage conversion. Finally, this work confirmed the neurogenic effect of Sox 2 first reported by Niu et al. (2013). Although this is somewhat puzzling, given the classical role of Sox 2 as a stem-cell maintenance factor, recent work also shows that it primes the epigenetic landscape in adult hippocampal progenitors for expression of neurogenic genes (Amador-Arjona et al. 2015). Perhaps Sox2 does the same work also in the above-described reprogramming scenarios.

Finally, the Chen laboratory made the very surprising observation that retrovirus-mediated NeuroD1 alone was sufficient to drive reactive astroglia and NG2 glia (using gfap and NG2 promoter-controlled retroviral vectors) of the adult mouse cerebral cortex with unprecedented efficiency toward neurogenesis in the absence of additional injury, besides that caused by virus injection, and the induced neurons fairly rapidly developed remarkable electrophysiological properties (Guo et al. 2014). Given the emerging concept that glial cells acquire stem-cell-like properties following injury (Dimou and Gotz 2014), it will be of obvious interest to assess the contribution of the virus injection-induced injury, if any, to the reprogramming process.

An altogether different approach developed by the Arlotta laboratory aims at reprogram- 
ming one neuron type into another. Rouaux and Arlotta (2010) showed that striatal progenitors that normally give rise to medium spiny neurons can be reprogrammed into pyramidallike neurons on forced expression of the transcription factor Fezf2 (Fig. 2). Remarkably, these neurons can project to subcortical targets, including the spinal cord, consistent with the role of Fezf2 in imposing a corticofugal projection neuron identity. This Fezf2 effect extends into early postmitotic life, as illustrated by the fact that callosal projection neurons can still be converted into corticofugal neurons during the first postnatal days, but lose such potential on closure of a critical, molecularly not-yet-defined window of nuclear plasticity (Rouaux and Arlotta 2013). A key question will be how to reopen this window of plasticity, evidently imposed by epigenetic modification in the course of cell differentiation. One exciting possibility may be to render these cells capable of undergoing cell proliferation. Although this sounds a priori violating the fact that neurons are per definition postmitotic entities, studies in the adult heart have shown that bona fide postmitotic cells can be enticed to enter cell cycle without losing their cellular specification even in vivo on expression of specific microRNAs (Eulalio et al. 2012). It will be of great intellectual and technical value to learn whether postmitotic neurons are susceptible to similar manipulations.

Future Perspectives of Engineering Neurogenesis Outside Physiological Neurogenic Niches

Although the above-discussed findings provide strong evidence for the principal possibility of engineering neurogenesis in regions of the adult brain, which lack any physiologically relevant degree of neuron production, the question remains to what extent this will enable us to utilize reprogramming strategies for brain repair. There are several issues to be dealt with before we can realistically hope to translate the experimental studies into a clinical context.

First of all, although reprogramming transcription factors are powerful tools to change the identity of cells, it remains to be explored whether the new phenotype corresponds to a "real" identity or rather reflects a chimeric state. Transcriptome studies of direct reprogrammed fibroblasts typically emphasize the similarity between the induced and naturally born neurons, but, nonetheless, cannot but acknowledge differences that appear to be the more pronounced the more terminally differentiated the cell of origin has been (Marro et al. 2011). This notion is of great significance when potentially considering reprogramming strategies within the adult human brain in which most cells are postmitotic, possibly with exception of slowly cycling OPCs (Yeung et al. 2014). The precise mechanisms underlying reprogramming are still poorly understood. A study in fibroblasts revealed that ascl1-induced conversion into neurons relies on this transcription factor's capacity of accessing closed chromatin, but only when these loci are in a defined trivalent state (as defined by specific active and repressive histone modifications), reprogramming can occur (Wapinski et al. 2013). However, it remains unclear whether any of the nonneuronal cells retain such trivalent state into adulthood, especially in aged human beings, in which the need for new neurons may become most pressing. If the molecular underpinnings of reprogramming are still ill understood, even more mysterious is how morphologically complex cells will metamorphose into neurons. Considering the tremendous complexity of adult human astrocytes (Oberheim et al. 2009), it will be fascinating to see how these cells remodel their astrocytic process into neuronal ones, an issue perhaps to be addressed by twophoton live imaging in models of cortical reprogramming, which allow for the access required for in vivo imaging. Yet, given that rather complex radial glial cells manage to generate neurons (Noctor et al. 2001), it may not be entirely hopeless that other cells of equal complexity could achieve this. Live imaging could also reveal crucial information as to whether reprogramming takes place directly, as suggested by in vitro studies (Heinrich et al. 2010), or requires proliferation. After all, a proliferative metamorphosis may ultimately allow for asym- 
metric cell division, by which not only a new neuron may be generated but ideally a cell of the original identity regenerated, thus avoiding depletion of functionally important cells.

A further challenge concerns the issue of functional integration into the neuronal circuitry. Functional integration may indeed be a prerequisite for long-term survival (Tashiro et al. 2006). Although early data suggest that induced neurons derived from in vitro as well as in vivo reprogrammed cells exhibit electrical properties of neurons, receive synaptic input, and, at least in vitro, are capable of generating synaptic output, it remains to be shown whether these cells incorporate in a meaningful manner. Failure to do so may not only compromise their chances for survival, but compromise circuit function. Many neurological diseases are recognized to be caused by defects in connectivity that may be as severe as in epilepsy or more subtle like in autism or schizophrenia. In this context, physiological adult neurogenesis may serve as a model of how new neurons are incorporated to smoothly modify circuit function. The studies of the Song laboratory have shown the important "chaperone" role of parvalbumin-positive interneurons for regulating genesis and differentiation of adult-born dentate granule neurons (Ge et al. 2006; Song et al. 2012, 2013). More generally, integration takes place in a very orderly fashion (Deshpande et al. 2013), suggesting that integration is a process of reciprocity between new neurons and preexisting circuitries. Incorporation of induced neurons derived from reprogrammed cells is likely to require similar interactions with chaperone cells.

Finally, for most neurodegenerative diseases, such as Alzheimer's disease, stroke and multiple sclerosis (MS), do not affect single cell types in clean isolation, but involve the entire nervous tissue comprising neurons, glia, microglia, and blood-borne immune cells, reprogramming may not be a viable strategy for brain repair after all, if this does not take into account the microenvironmental changes, such as, for example, the inflammatory response that these diseases induce. Thus, reprogramming strategies must go hand in hand with interventions that create a conducive microenvironment (Heinrich et al. 2015).

\section{DIRECTED DIFFERENTIATION OF ADULT NEURAL STEM CELLS}

The focus on targeted engineering of endogenous NSPCs (or cells that do not generate neuronal cells under physiologically conditions) has been to enhance the generation of neurons or to induce neuronal differentiation. However, diseases of the CNS obviously also affect the functional integrity or lead to a loss of glial cells. Given this, especially the NSPC-derived generation of oligodendrocytes, that are, for example, disease targets in chronic demyelinating diseases such as MS, has gained significant attention (Jadasz et al. 2012). Notably, NSPCs in the SVZ generate oligodendrocytes under physiological conditions, and the formation of oligodendrocytes is enhanced after demyelinating lesions (Menn et al. 2006; Xing et al. 2014). Thus, the identification of signaling pathways that mediate oligodendrocytic differentiation is important and may lead to the development of novel strategies to enhance oligodendrogenesis in the context of demyelinating disease (Fig. 3). This is true for the recently identified role for WNT signaling to expand the NSPCderived oligodendrocytic lineage, the up-regulation of chordin that directs cells toward an oligodendrocytic fate on demyelination in the corpus callosum, and for the finding that loss of SIRT1 enhances oligodendrogenesis (even though it remains unclear whether the enhanced generation of oligodendrocytes on loss of SIRT1 depends on NSPCs) (Fig. 3) (Jablonska et al. 2010; Ortega et al. 2013; Rafalski et al. 2013).

The situation in the hippocampal stem-cell niche is distinct compared with the SVZ as only very few (if any) oligodendrocytes are generated under normal conditions (Zhao et al. 2006). However, it has been recently shown that the fate of newborn cells can be redirected from a neuronal toward an oligodendrocytic fate by the overexpression of the basic helix-loop-helix (bHLH) transcription factor ascl1 (Fig. 3) (Jessberger et al. 2008). Even though induced oligo- 


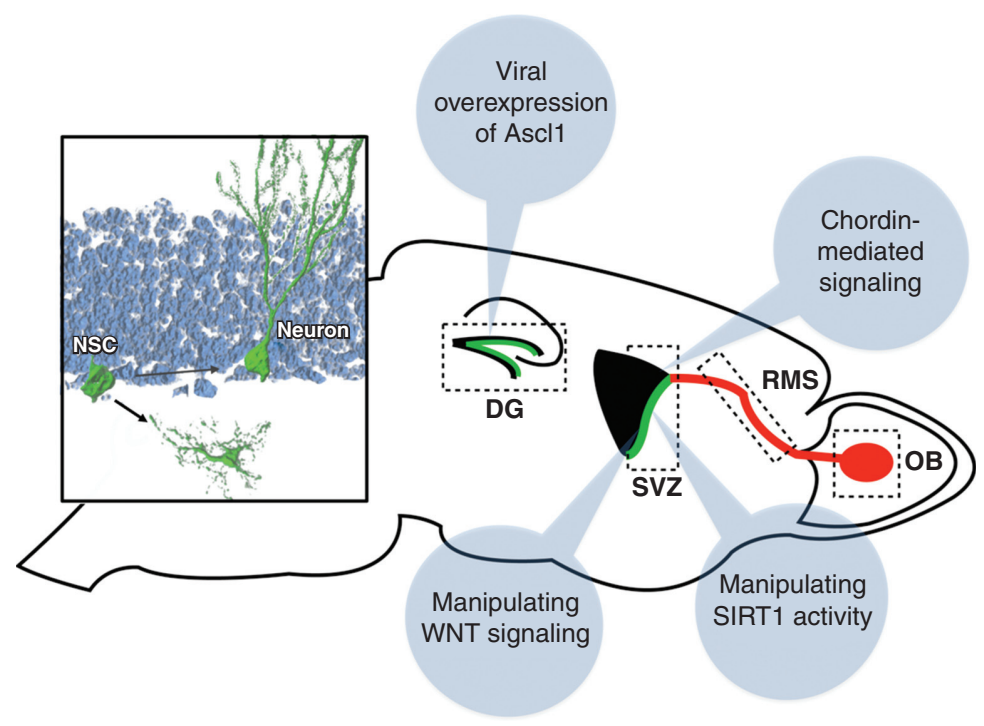

Figure 3. Mechanisms to direct the differentiation of endogenous neural stem/progenitor cells (NSPCs). Shown are several experimental strategies to enhance neural subtype specific differentiation (e.g., through modulating WNT signaling) or to direct the fate of newborn cells from a neuronal toward the glial lineage (e.g., through ascl1 overexpression in hippocampal NSPCs; shown in the left inset). NSC, Neural stem cell; DG, dentate gyrus; SVZ, subventricular zone; RMS, rostral migratory stream; OB, olfactory bulb. (Figure courtesy of Dr. S.M.G. Braun, Brain Research Institute, Zurich, Switzerland.)

dendrogenesis appears to be capable to generate myelin, it remains unclear whether newborn oligodendrocytes generated through directed differentiation turn out to be sufficient to enhance remyelination in the context of injury (Goldman and Natesan 2008; Jessberger and Gage 2009).

However, focusing the attempts to generate functional glial cells - in addition to enhanced or induced generation of neurons-will certainly be of growing interest over the next year but will require the development of novel tools to faithfully control the generation of glial cells within the adult brain.

\section{FUTURISTIC BRAIN REPAIR}

In some of the most devastating brain diseases like Alzheimer or stroke, it is not just a single type of neuron that degenerates but an entire circuit that needs to be replaced. How to rebuild such highly structured assemblies of neurons (and glia) by reprogramming? Will it be required to provide point-by-point instructions in the form of specific transcription factors that instruct the genesis of all the plethora of neuronal and glial subtypes to recreate for instance a piece of infarcted cortex? Here, we can open only a highly speculative window into the solution by referring to the remarkable degree of self-organization that neural stem cells derived from embryonic stem cells exhibit when exposed to an appropriately permissive environment eventually resulting in the formation of cerebral organoids (Kadoshima et al. 2013; Lancaster et al. 2013). Too little is known of the underlying logic of this self-organizing process, but the fact that somatic cells such as fibroblasts can be reprogrammed into multipotent neural-stem-cell-like cells (Lujan and Wernig 2012) gives some cause for hope that this may ultimately go along with gaining not only the capacity for neuro- but even "cerebrogenesis."

\section{SUMMARY}

Injury to the adult CNS, through acute or chronic disease, often results in the loss or func- 
tional impairment of neuronal and/or glial cells. Recent advances indicated the possibility to engineer the fate and potency of NSPCs or other resident cells to serve as a source for cell replacement of lost structures, opening novel possibilities in the context of regenerative medicine. However, most approaches currently pursued require invasive strategies to genetically modify adult brain cells for fate direction or reprogramming, indicating that these highly experimental approaches are still far from clinical application. Additional proof-of-concept experiments are required that evaluate the potential of NSPC engineering to generate new cells with the aim to replace lost tissue in the context of acute or chronic diseases such as stroke or MS.

\section{REFERENCES}

Alvarez-Buylla A, Lim DA. 2004. For the long run: Maintaining germinal niches in the adult brain. Neuron 41: 683-686.

Amador-Arjona A, Cimadamore F, Huang CT, Wright R, Lewis S, Gage FH, Terskikh AV. 2015. SOX2 primes the epigenetic landscape in neural precursors enabling proper gene activation during hippocampal neurogenesis. Proc Natl Acad Sci 112: E1936-E1945.

Amamoto R, Arlotta P. 2014. Development-inspired reprogramming of the mammalian central nervous system. Science 343: 1239882.

Berninger B, Costa MR, Koch U, Schroeder T, Sutor B, Grothe B, Götz M. 2007. Functional properties of neurons derived from in vitro reprogrammed postnatal astroglia. J Neurosci 27: 8654-8664.

Brill MS, Ninkovic J, Winpenny E, Hodge RD, Ozen I, Yang R, Lepier A, Gascon S, Erdelyi F, Szabo G, et al. 2009. Adult generation of glutamatergic olfactory bulb interneurons. Nat Neurosci 12: 1524-1533.

Buffo A, Vosko MR, Erturk D, Hamann GF, Jucker M, Rowitch D, Götz M. 2005. Expression pattern of the transcription factor Olig2 in response to brain injuries: Implications for neuronal repair. Proc Natl Acad Sci 102: 1818318188.

Bush TG, Savidge TC, Freeman TC, Cox HJ, Campbell EA, Mucke L, Johnson MH, Sofroniew MV. 1998. Fulminant jejuno-ileitis following ablation of enteric glia in adult transgenic mice. Cell 93: 189-201.

Cerpa W, Gambrill A, Inestrosa NC, Barria A. 2011. Regulation of NMDA-receptor synaptic transmission by Wnt signaling. J Neurosci 31: 9466-9471.

Costa MR, Götz M, Berninger B. 2010. What determines neurogenic competence in glia? Brain Res Rev 63: 47-59.

Deng W, Saxe MD, Gallina IS, Gage FH. 2009. Adult-born hippocampal dentate granule cells undergoing matura- tion modulate learning and memory in the brain. $\mathrm{J} \mathrm{Neu}$ rosci 29: 13532-13542.

Deng W, Aimone JB, Gage FH. 2010. New neurons and new memories: How does adult hippocampal neurogenesis affect learning and memory? Nat Rev Neurosci 11: 339350.

Deshpande A, Bergami M, Ghanem A, Conzelmann KK, Lepier A, Götz M, Berninger B. 2013. Retrograde monosynaptic tracing reveals the temporal evolution of inputs onto new neurons in the adult dentate gyrus and olfactory bulb. Proc Natl Acad Sci 110: E1152-E1161.

Dimou L, Götz M. 2014. Glial cells as progenitors and stem cells: New roles in the healthy and diseased brain. Physiol Rev 94: 709-737.

Doetsch F, Caille I, Lim DA, Garcia-Verdugo JM, AlvarezBuylla A. 1999. Subventricular zone astrocytes are neural stem cells in the adult mammalian brain. Cell 97: 703716.

Dupret D, Revest JM, Koehl M, Ichas F, De Giorgi F, Costet P, Abrous DN, Piazza PV. 2008. Spatial relational memory requires hippocampal adult neurogenesis. PLoS ONE 3: e1959.

Eulalio A, Mano M, Dal Ferro M, Zentilin L, Sinagra G, Zacchigna S, Giacca M. 2012. Functional screening identifies miRNAs inducing cardiac regeneration. Nature 492: 376-381.

Gage F. 2000. Mammalian neural stem cells. Science 287: $1433-1438$.

Gage FH, Temple S. 2013. Neural stem cells: Generating and regenerating the brain. Neuron 80: 588-601.

Garcia AD, Doan NB, Imura T, Bush TG, Sofroniew MV. 2004. GFAP-expressing progenitors are the principal source of constitutive neurogenesis in adult mouse forebrain. Nat Neurosci 7: 1233-1241.

Ge S, Goh EL, Sailor KA, Kitabatake Y, Ming GL, Song H. 2006. GABA regulates synaptic integration of newly generated neurons in the adult brain. Nature 439: 589-593.

Goldman SA, Natesan S. 2008. A niche-defying feat: Induced oligoneogenesis in the adult dentate gyrus. Cell Stem Cell 3: 125-126.

Göritz C, Dias DO, Tomilin N, Barbacid M, Shupliakov O, Frisén J. 2011. A pericyte origin of spinal cord scar tissue. Science 333: 238-242.

Grande A, Sumiyoshi K, Lopez-Juarez A, Howard J, Sakthivel B, Aronow B, Campbell K, Nakafuku M. 2013. Environmental impact on direct neuronal reprogramming in vivo in the adult brain. Nat Commun 4: 2373.

Gu Y, Arruda-Carvalho M, Wang J, Janoschka SR, Josselyn SA, Frankland PW, Ge S. 2012. Optical controlling reveals time-dependent roles for adult-born dentate granule cells. Nat Neurosci 15: 1700-1706.

Guo Z, Zhang L, Wu Z, Chen Y, Wang F, Chen G. 2014. In vivo direct reprogramming of reactive glial cells into functional neurons after brain injury and in an $\mathrm{Alz}$ heimer's disease model. Cell Stem Cell 14: 188-202.

Hack MA, Saghatelyan A, de Chevigny A, Pfeifer A, AsheryPadan R, Lledo PM, Götz M. 2005. Neuronal fate determinants of adult olfactory bulb neurogenesis. Nat Neurosci 8: $865-872$.

Heinrich C, Blum R, Gascon S, Masserdotti G, Tripathi P, Sanchez R, Tiedt S, Schroeder T, Götz M, Berninger B. 
2010. Directing astroglia from the cerebral cortex into subtype specific functional neurons. PLoS Biol 8: e1000373.

Heinrich C, Bergami M, Gascon S, Lepier A, Vigano F, Dimou L, Sutor B, Berninger B, Götz M. 2014. Sox2-mediated conversion of NG2 glia into induced neurons in the injured adult cerebral cortex. Stem Cell Rep 3: 1000 1014.

Heinrich C, Spagnoli FM, Berninger B. 2015. In vivo reprogramming for tissue repair. Nat Cell Biol 17: 204-211.

Heins N, Malatesta P, Cecconi F, Nakafuku M, Tucker KL, Hack MA, Chapouton P, Barde YA, Götz M. 2002. Glial cells generate neurons: The role of the transcription factor Pax6. Nat Neurosci 5: 308-315.

Imayoshi I, Ohtsuka T, Metzger D, Chambon P, Kageyama R. 2006. Temporal regulation of Cre recombinase activity in neural stem cells. Genesis 44: 233-238.

Imayoshi I, Sakamoto M, Ohtsuka T, Takao K, Miyakawa T, Yamaguchi M, Mori K, Ikeda T, Itohara S, Kageyama R. 2008. Roles of continuous neurogenesis in the structural and functional integrity of the adult forebrain. $\mathrm{Nat} \mathrm{Neu-}$ rosci 11: 1153-1161.

Jablonska B, Aguirre A, Raymond M, Szabo G, Kitabatake Y, Sailor KA, Ming GL, Song H, Gallo V. 2010. Chordininduced lineage plasticity of adult SVZ neuroblasts after demyelination. Nat Neurosci 13: 541-550.

Jadasz JJ, Aigner L, Rivera FJ, Kury P. 2012. The remyelination philosopher's stone: Stem and progenitor cell therapies for multiple sclerosis. Cell Tissue Res 349: 331-347.

Jessberger S, Gage FH. 2009. Fate plasticity of adult hippocampal progenitors: Biological relevance and therapeutic use. Trends Pharmacol Sci 30: 61-65.

Jessberger S, Toni N, Clemenson GD Jr, Ray J, Gage FH. 2008. Directed differentiation of hippocampal stem/progenitor cells in the adult brain. Nat Neurosci 11: 888-893.

Jessberger S, Clark RE, Broadbent NJ, Clemenson GD Jr, Consiglio A, Lie DC, Squire LR, Gage FH. 2009. Dentate gyrus-specific knockdown of adult neurogenesis impairs spatial and object recognition memory in adult rats. Learn Mem 16: 147-154.

Kadoshima T, Sakaguchi H, Nakano T, Soen M, Ando S, Eiraku M, Sasai Y. 2013. Self-organization of axial polarity, inside-out layer pattern, and species-specific progenitor dynamics in human ES cell-derived neocortex. Proc Natl Acad Sci 110: 20284-20289.

Karow M, Sanchez R, Schichor C, Masserdotti G, Ortega F, Heinrich C, Gascon S, Khan MA, Lie DC, Dellavalle A, et al. 2012. Reprogramming of pericyte-derived cells of the adult human brain into induced neuronal cells. Cell Stem Cell 11: 471-476.

Kondo T, Raff M. 2000. Basic helix-loop-helix proteins and the timing of oligodendrocyte differentiation. Development 127: 2989-2998.

Kondo T, Raff M. 2004. Chromatin remodeling and histone modification in the conversion of oligodendrocyte precursors to neural stem cells. Genes Dev 18: 2963-2972.

Kriegstein A, Alvarez-Buylla A. 2009. The glial nature of embryonic and adult neural stem cells. Annu Rev Neurosci 32: $149-184$.

Lancaster MA, Renner M, Martin CA, Wenzel D, Bicknell LS, Hurles ME, Homfray T, Penninger JM, Jackson AP,
Knoblich JA. 2013. Cerebral organoids model human brain development and microcephaly. Nature 501: 373-379.

Lie DC, Colamarino SA, Song HJ, Desire L, Mira H, Consiglio A, Lein ES, Jessberger S, Lansford H, Dearie AR, et al. 2005. Wnt signalling regulates adult hippocampal neurogenesis. Nature 437: 1370-1375.

Lindvall O. 2013. Developing dopaminergic cell therapy for Parkinson's disease-Give up or move forward? Mov Disord 28: 268-273.

Lujan E, Wernig M. 2012. The many roads to Rome: Induction of neural precursor cells from fibroblasts. Curr Opin Genet Dev 22: 517-522.

Magnusson JP, Goritz C, Tatarishvili J, Dias DO, Smith EM, Lindvall O, Kokaia Z, Frisen J. 2014. A latent neurogenic program in astrocytes regulated by Notch signaling in the mouse. Science 346: 237-241.

Malatesta P, Hartfuss E, Götz M. 2000. Isolation of radial glial cells by fluorescent-activated cell sorting reveals a neuronal lineage. Development 127: 5253-5263.

Marro S, Pang ZP, Yang N, Tsai MC, Qu K, Chang HY, SÃ $\frac{1}{4}$ dhof TC, Wernig M. 2011. Direct lineage conversion of terminally differentiated hepatocytes to functional neurons. Cell Stem Cell 9: 374-382.

Maserdotti G, Gillotin S, Drechsel D, Irmler M, Jorgensen $\mathrm{H}$, Sass S, Theis FJ, Beckers J, Sutor B, Berninger B, et al. 2015. Transcriptional mechanisms of proneural factors and REST in regulating neuronal reprogramming of astrocytes. Cell Stem Cell 17: 74-88.

Menn B, Garcia-Verdugo JM, Yaschine C, Gonzalez-Perez O, Rowitch D, Alvarez-Buylla A. 2006. Origin of oligodendrocytes in the subventricular zone of the adult brain. $J$ Neurosci 26: 7907-7918.

Mignone JL, Roig-Lopez JL, Fedtsova N, Schones DE, Manganas LN, Maletic-Savatic M, Keyes WM, Mills AA, Gleiberman A, Zhang MQ, et al. 2007. Neural potential of a stem cell population in the hair follicle. Cell Cycle 6: 2161-2170.

Ming GL, Song H. 2011. Adult neurogenesis in the mammalian brain: Significant answers and significant questions. Neuron 70: 687-702.

Niu W, Zang T, Zou Y, Fang S, Smith DK, Bachoo R, Zhang CL. 2013. In vivo reprogramming of astrocytes to neuroblasts in the adult brain. Nat Cell Biol 15: 1164-1175.

Noctor SC, Flint AC, Weissman TA, Dammerman RS, Kriegstein AR. 2001. Neurons derived from radial glial cells establish radial units in neocortex. Nature 409: 714-720.

Oberheim NA, Takano T, Han X, He W, Lin JH, Wang F, Xu Q, Wyatt JD, Pilcher W, Ojemann JG, et al. 2009. Uniquely hominid features of adult human astrocytes. J Neurosci 29: 3276-3287.

Ortega F, Gascon S, Masserdotti G, Deshpande A, Simon C, Fischer J, Dimou L, Chichung Lie D, Schroeder T, Berninger B. 2013. Oligodendrogliogenic and neurogenic adult subependymal zone neural stem cells constitute distinct lineages and exhibit differential responsiveness to Wnt signalling. Nat Cell Biol 15: 602-613.

Rafalski VA, Ho PP, Brett JO, Ucar D, Dugas JC, Pollina EA, Chow LM, Ibrahim A, Baker SJ, Barres BA, et al. 2013. Expansion of oligodendrocyte progenitor cells following 
B. Berninger and S. Jessberger

SIRT1 inactivation in the adult brain. Nat Cell Biol 15: 614-624.

Rouaux C, Arlotta P. 2010. Fezf2 directs the differentiation of corticofugal neurons from striatal progenitors in vivo. Nat Neurosci 13: 1345-1347.

Rouaux C, Arlotta P. 2013. Direct lineage reprogramming of post-mitotic callosal neurons into corticofugal neurons in vivo. Nat Cell Biol 15: 214-221.

Sahay A, Scobie KN, Hill AS, O'Carroll CM, Kheirbek MA, Burghardt NS, Fenton AA, Dranovsky A, Hen R. 2011. Increasing adult hippocampal neurogenesis is sufficient to improve pattern separation. Nature 472: 466-470.

Sarkar A, Hochedlinger K. 2013. The sox family of transcription factors: Versatile regulators of stem and progenitor cell fate. Cell Stem Cell 12: 15-30.

Saxe MD, Battaglia F, Wang JW, Malleret G, David DJ, Monckton JE, Garcia AD, Sofroniew MV, Kandel ER, Santarelli L, et al. 2006. Ablation of hippocampal neurogenesis impairs contextual fear conditioning and synaptic plasticity in the dentate gyrus. Proc Natl Acad Sci 103: 1750117506.

Saxe MD, Malleret G, Vronskaya S, Mendez I, Garcia AD Sofroniew MV, Kandel ER, Hen R. 2007. Paradoxical influence of hippocampal neurogenesis on working memory. Proc Natl Acad Sci 104: 4642-4646.

Shors TJ, Miesegaes G, Beylin A, Zhao M, Rydel T, Gould E. 2001. Neurogenesis in the adult is involved in the formation of trace memories. Nature 410: 372-376.

Snyder JS, Hong NS, McDonald RJ, Wojtowicz JM. 2005. A role for adult neurogenesis in spatial long-term memory. Neuroscience 130: 843-852.

Song J, Zhong C, Bonaguidi MA, Sun GJ, Hsu D, Gu Y, Meletis K, Huang ZJ, Ge S, Enikolopov G, et al. 2012. Neuronal circuitry mechanism regulating adult quiescent neural stem-cell fate decision. Nature 489: 150-154.

Song J, Sun J, Moss J, Wen Z, Sun GJ, Hsu D, Zhong C, Davoudi H, Christian KM, Toni N, et al. 2013. Parvalbumin interneurons mediate neuronal circuitry-neurogenesis coupling in the adult hippocampus. Nat Neurosci 16: $1728-1730$.

Sternson SM, Roth BL. 2014. Chemogenetic tools to interrogate brain functions. Annu Rev Neurosci 37: 387-407.

Tashiro A, Sandler VM, Toni N, Zhao C, Gage FH. 2006. NMDA-receptor-mediated, cell-specific integration of new neurons in adult dentate gyrus. Nature 442: 929933.

Tashiro A, Makino H, Gage FH. 2007. Experience-specific functional modification of the dentate gyrus through adult neurogenesis: A critical period during an immature stage. J Neurosci 27: 3252-3259.

Temprana SG, Mongiat LA, Yang SM, Trinchero MF, Alvarez DD, Kropff E, Giacomini D, Beltramone N, Lanuza GM, Schinder AF. 2015. Delayed coupling to feedback inhibition during a critical period for the integration of adultborn granule cells. Neuron 85: 116-130.

Torper O, Pfisterer U, Wolf DA, Pereira M, Lau S, Jakobsson J, Bjorklund A, Grealish S, Parmar M. 2013. Generation of induced neurons via direct conversion in vivo. Proc Natl Acad Sci 110: 7038-7043.

Vierbuchen T, Ostermeier A, Pang ZP, Kokubu Y, Sudhof TC, Wernig M. 2010. Direct conversion of fibroblasts to functional neurons by defined factors. Nature 463: $1035-$ 1041.

Wapinski OL, Vierbuchen T, Qu K, Lee QY, Chanda S, Fuentes DR, Giresi PG, Ng YH, Marro S, Neff NF, et al. 2013. Hierarchical mechanisms for direct reprogramming of fibroblasts to neurons. Cell 155: 621-635.

Xing YL, Röth PT, Stratton JA, Chuang BH, Danne J, Ellis SL, Ng SW, Kilpatrick TJ, Merson TD. 2014. Adult neural precursor cells from the subventricular zone contribute significantly to oligodendrocyte regeneration and remyelination. J Neurosci 34: 14128-14146.

Yeung MS, Zdunek S, Bergmann O, Bernard S, Salehpour M, Alkass K, Perl S, Tisdale J, Possnert G, Brundin L, et al. 2014. Dynamics of oligodendrocyte generation and myelination in the human brain. Cell 159: 766-774.

Yu DX, Marchetto MC, Gage FH. 2013. Therapeutic translation of iPSCs for treating neurological disease. Cell Stem Cell 12: 678-688.

Yu DX, Di Giorgio FP, Yao J, Marchetto MC, Brennand K, Wright R, Mei A, McHenry L, Lisuk D, Grasmick JM, et al. 2014. Modeling hippocampal neurogenesis using human pluripotent stem cells. Stem Cell Rep 2: 295-310.

Zhao C, Teng EM, Summers RG Jr, Ming GL, Gage FH. 2006. Distinct morphological stages of dentate granule neuron maturation in the adult mouse hippocampus. $J$ Neurosci 26: 3-11. 


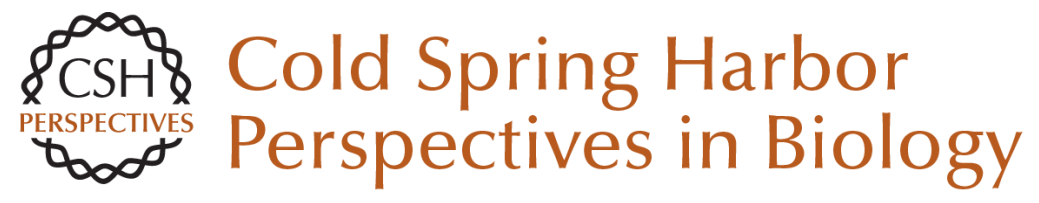

\section{Engineering of Adult Neurogenesis and Gliogenesis}

Benedikt Berninger and Sebastian Jessberger

Cold Spring Harb Perspect Biol 2016; doi: 10.1101/cshperspect.a018861 originally published online April 18, 2016

\section{Subject Collection Neurogenesis}

Adult Neurogenesis and Psychiatric Disorders Eunchai Kang, Zhexing Wen, Hongjun Song, et al.

Neuronal Circuitry Mechanisms Regulating Adult Mammalian Neurogenesis Juan Song, Reid H.J. Olsen, Jiaqi Sun, et al.

Neurogenesis in the Developing and Adult Brain

--Similarities and Key Differences

Magdalena Götz, Masato Nakafuku and David Petrik

Genetics and Epigenetics in Adult Neurogenesis Jenny Hsieh and Xinyu Zhao

The Adult Ventricular-Subventricular Zone (V-SVZ) and Olfactory Bulb (OB) Neurogenesis Daniel A. Lim and Arturo Alvarez-Buylla

Diversity of Neural Precursors in the Adult Mammalian Brain Michael A. Bonaguidi, Ryan P. Stadel, Daniel A. Berg, et al.

Detection and Phenotypic Characterization of Adult Neurogenesis $H$. Georg Kuhn, Amelia J. Eisch, Kirsty Spalding, et al.

Maturation and Functional Integration of New Granule Cells into the Adult Hippocampus Nicolas Toni and Alejandro F. Schinder
Adult Olfactory Bulb Neurogenesis

Pierre-Marie Lledo and Matt Valley

Adult Neurogenesis in Fish Julia Ganz and Michael Brand

In Vitro Models for Neurogenesis Hassan Azari and Brent A. Reynolds
Engineering of Adult Neurogenesis and Gliogenesis
Benedikt Berninger and Sebastian Jessberger
Computational Modeling of Adult Neurogenesis James B. Aimone
Control of Adult Neurogenesis by Short-Range Morphogenic-Signaling Molecules Youngshik Choe, Samuel J. Pleasure and Helena Mira

Adult Neurogenesis: An Evolutionary Perspective Gerd Kempermann

Epilepsy and Adult Neurogenesis

Sebastian Jessberger and Jack M. Parent

For additional articles in this collection, see http://cshperspectives.cshlp.org/cgi/collection/

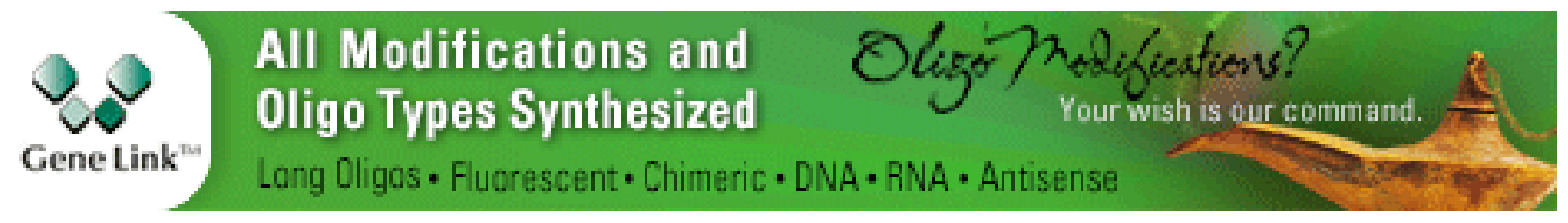


For additional articles in this collection, see http://cshperspectives.cshlp.org/cgi/collection/

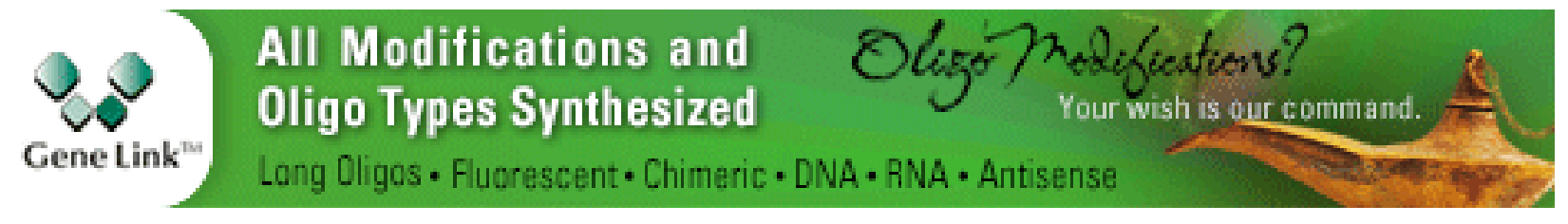

Copyright @ 2016 Cold Spring Harbor Laboratory Press; all rights reserved 